\title{
Is a Previously or Currently Reduced Testosterone Level in Male Patients with Type 2 Diabetes Mellitus a Risk Factor for the Development of Coronary Artery Disease? A Systematic Review and Meta-analysis
}

Feng Huang (iD

Received: February 23, 2018 / Published online: April 4, 2018

(C) The Author(s) 2018

\begin{abstract}
Introduction: We aimed to systematically investigate the association between testosterone level and cardiovascular risk in male patients with type 2 diabetes mellitus (T2DM) by comparing male T2DM patients with low testosterone levels to male T2DM patients with normal testosterone levels at baseline in terms of the number of cases of coronary artery disease (CAD).

Methods: Online databases were carefully searched for studies relating to testosterone, diabetes mellitus, and cardiovascular risk by using the search terms 'testosterone,' 'diabetes mellitus,' and 'coronary artery/cardiovascular disease.' The only endpoint in this analysis was $\mathrm{CAD} /$ atherosclerosis/coronary plaque/major adverse coronary event prior to or following testosterone reduction at baseline. The analytical parameters used in this analysis were the risk
\end{abstract}

Enhanced content To view enhanced content for this article go to https://doi.org/10.6084/m9.figshare. 6000218 .

F. Huang ( $\square)$

Institute of Cardiovascular Diseases and Guangxi

Key Laboratory Base of Precision Medicine in

Cardio-cerebrovascular Diseases Control and

Prevention, The First Affiliated Hospital of Guangxi

Medical University, Nanning, Guangxi,

People's Republic of China

e-mail: huangfeng7925@163.com ratio (RR) with the 95\% confidence interval (CI), as obtained using the RevMan 5.3 software. Results: 3467 male patients with T2DM (1079 patients with a low testosterone level versus 2388 patients with a normal testosterone level) were included. The results of this analysis showed that when a random effects model was used, a higher risk of CAD/cardiovascular disease was observed in diabetic patients with a low testosterone level than in those with a normal testosterone level (RR 1.24, 95\% CI $0.94-1.63 ; P=0.13)$. However, the difference in risk was not statistically significant. Similarly, with a fixed effects model, a low testosterone level was associated with a higher $\mathrm{CAD} /$ cardiovascular risk of disease (RR 1.12, 95\% CI $0.98-1.34 ; P=0.08$ ); in this case, the difference in risk between the T2DM patients with low and normal testosterone levels approached statistical significance.

Conclusion: A previously or currently reduced testosterone level was not found to be statistically significantly associated with a high risk of $\mathrm{CAD} /$ cardiovascular disease in male patients with T2DM. However, the difference in risk between the T2DM patients with low and normal testosterone levels was observed to approach statistical significance.

Keywords: Cardiovascular disease; Coronary artery disease; Male; Testosterone; Type 2 diabetes mellitus 


\section{INTRODUCTION}

Type 2 diabetes mellitus (T2DM) is a growing threat to the health of many in their second or third age around the world [1]. Unfortunately, coronary artery disease (CAD), which is responsible for a high percentage of all deaths globally, is often also a long-term complication of T2DM [2]. Recently, research has shown an important link between a low testosterone level and the development of atherosclerosis in male patients [3]. However, the association between a low testosterone level and $\mathrm{CAD} /$ cardiovascular risk is still being debated [4]. Therefore, by comparing CAD rates in diabetic patients with low and normal testosterone levels at baseline, we aimed to systematically investigate this issue in male patients with T2DM.

\section{METHODS}

\section{Searched Databases and Strategies}

The Cochrane database of randomized controlled trials, PubMed/Medline, and EMBASE were carefully searched for studies related to testosterone, diabetes mellitus, and CAD/cardiovascular risk using the search terms 'testosterone,' 'diabetes mellitus,' and 'cardiovascular disease.' The term 'cardiovascular disease' was later interchanged with the terms 'atherosclerosis' and 'coronary artery disease.' Abbreviations such as T2DM, DM, CVD, and CAD were also used to further enhance this search process. We only searched for articles published in English.

\section{Inclusion and Exclusion Criteria}

During this selection process, various inclusion and exclusion criteria were applied to all of the articles. The following inclusion criteria were used:

- Studies including only male patients with T2DM

- Studies comparing diabetic patients with low testosterone levels to diabetic patients with normal testosterone levels
- Studies reporting the number of patients with CAD at baseline or during the follow-up period

The exclusion criteria were as follows:

- Studies that did not focus on male patients with T2DM

- Studies that did not compare diabetic patients with low testosterone levels to diabetic patients with normal testosterone levels

- Studies that did not report the number of patients with CAD at baseline or during the follow-up period.

\section{Endpoints}

The only endpoint in this analysis was CAD/ atherosclerosis/coronary plaque/major adverse coronary event prior to or following testosterone reduction.

Outcomes that were considered relevant in each study are recorded in Table 1.

\section{Data Extraction and Review}

The PRISMA guideline was followed [5]. The studies were carefully checked and important relevant data were extracted by the reviewer $(\mathrm{FH})$. The following data were extracted and cross-checked again:

- Author names

- Year of publication

- The type of study performed (randomized trial or observational cohort);

- The total numbers of patients with low and normal testosterone levels

- Baseline characteristics of the patients

- The patient enrollment period

- The testosterone level ranges that were considered to be low and normal

- The total number of patients with CAD

\section{Statistical Analysis}

The analytical parameters used were the risk ratio (RR) and the 95\% confidence interval (CI) obtained using the RevMan 5.3 software.

Heterogeneity was assessed via the $Q$ statistic test and the $I^{2}$ statistic test [6]. 
Table 1 Cardiovascular outcomes reported in the studies of interest

\begin{tabular}{lll}
\hline Study & Cardiovascular outcome reported & Time period \\
\hline Cheung et al. (2016) [7] & Coronary heart disease & At baseline \\
Farias et al. (2014) [8] & Coronary plaque & At baseline \\
Gianatti et al. (2016) [9] & Cardiovascular risk & At baseline \\
Hackett et al. (2016) [10] & Major adverse coronary events & At baseline \\
Liu et al. (2013) [11] & Coronary artery disease & At baseline \\
Muraleedharan et al. (2013) [12] & Pre-existing coronary vascular disease & At baseline \\
\hline
\end{tabular}

A $P$ value of $\leq 0.05$ was assumed to indicate statistical significance.

A fixed effects model $\left(I^{2}<50 \%\right)$ or a random effects model $\left(I^{2}>50 \%\right)$ was used depending on the value of $I^{2}$ obtained. In this analysis, both a fixed effects and a random effects were used during the subgroup assessment.

Sensitivity analyses were also carried out by excluding each of the studies in turn and conducting a new analysis following each exclusion.

\section{Ethics}

The meta-analysis reported here was based on previously conducted studies and did not include any studies with human participants or animals performed by any of the authors. Hence, ethical approval was not required.

\section{RESULTS}

\section{Searched Results}

Two hundred forty-nine (249) articles were obtained during the database search. After two reviewers had carefully reviewed the abstracts, 228 publications were excluded since they were either not directly related to the present research or they were duplicates. Twenty-one (21) full-text articles were assessed for eligibility. Further articles were eliminated for the following reasons:

- One article was a review article
- Ten articles reported studies that did not involve male patients with T2DM

- Four articles did not report the relevant study endpoint

Finally, only six articles [7-12] were selected for the present analysis (Fig. 1).

\section{General Features of the Studies}

A total of 3467 male patients with T2DM (1079 patients with a low testosterone level versus 2388 patients with a normal testosterone level) were included in this analysis (Table 2). Two randomized trials and four observational cohorts were considered. The patient enrollment period varied between the years 2002 and 2013. The ranges of testosterone levels along with other features of the studies included in this analysis are listed in Table 2.

\section{Baseline Characteristics of the Patients}

A summary of the baseline characteristics of the patients is shown in Table 3. Mean age ranged from 58.0 to 65.6 years. Duration of diabetes mellitus ranged from 6 to 10.5 years. In addition, during a two-month control phase, glycosylated hemoglobin ranged between $6.80 \%$ and $7.90 \%$. In terms of the baseline characteristics of the patients, there was almost no difference between the diabetic patients with low testosterone and those with normal testosterone levels. 


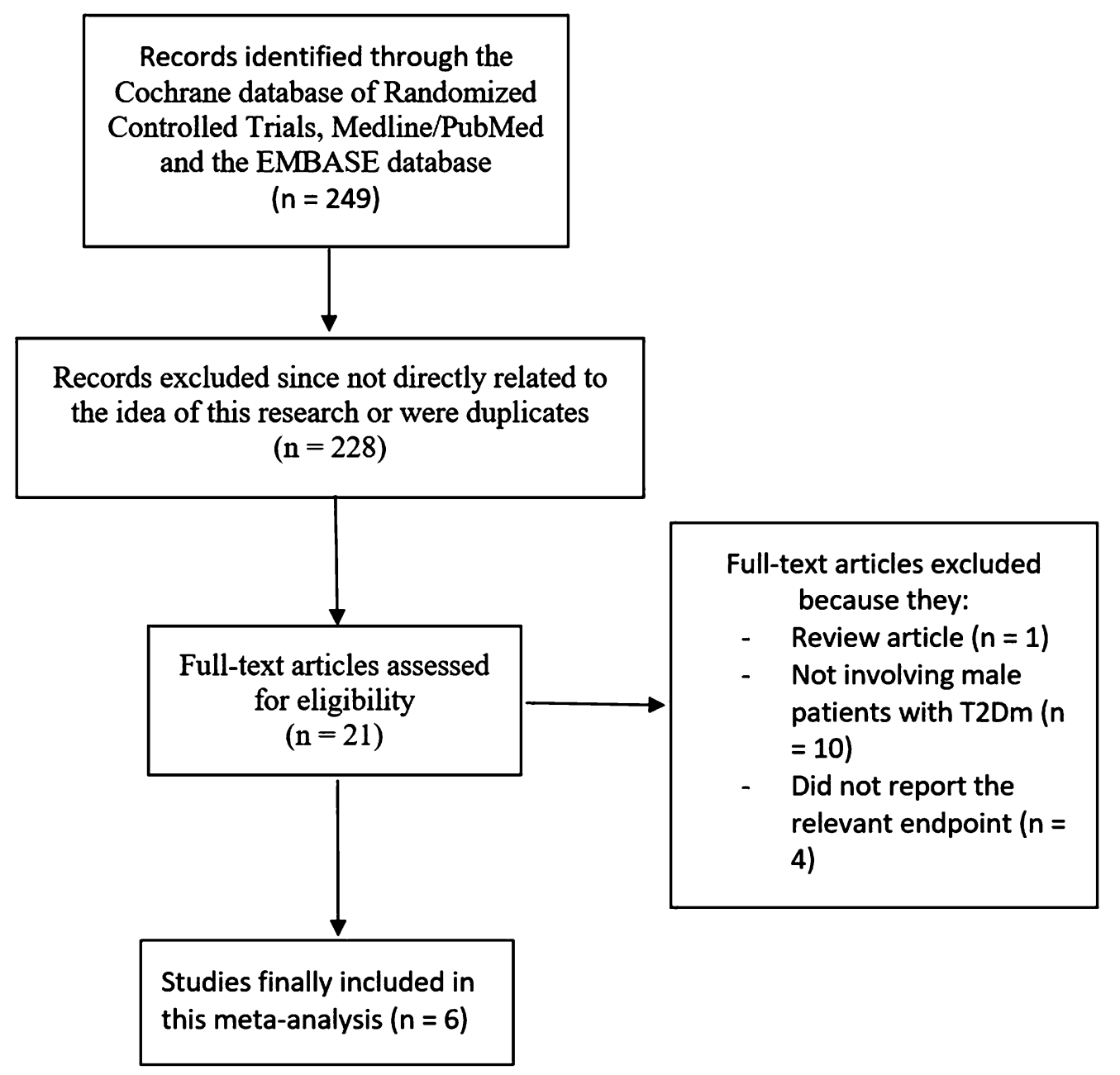

Fig. 1 Flow diagram representing the study selection process

\section{Association of a Low Testosterone Level with Cardiovascular Risk}

The results of this analysis showed that when a random effects model was used, diabetic patients with a low testosterone level were at a relatively high risk of $\mathrm{CAD} /$ cardiovascular disease (RR 1.24, 95\% CI 0.94-1.63; $P=0.13$; Fig. 2). However, the difference in CAD/cardiovascular disease risk between the low and normal testosterone T2DM patients was not statistically significant.

Similarly, when a fixed effects model was used, diabetic patients with a low testosterone level again were at a higher risk of $\mathrm{CAD} / \mathrm{car}$ diovascular disease than the diabetic patients with a normal testosterone level (RR 1.12, 95\%
CI 0.98-1.34; $P=0.08$; Fig. 3). In this case, even though the difference in $\mathrm{CAD} /$ cardiovascular disease risk between the low and normal testosterone T2DM patients was again not statistically significant, it did approach significance.

Sensitivity analysis was also carried out in order to confirm that the results of this analysis were not strongly influenced by the results from one of the studies in particular (Fig. 4).

The sensitivity analysis showed that the results of the analysis did not change significantly when any one of the following studies was excluded from the analysis: Cheung et al. [7] (RR 1.15, 95\% CI 0.88-1.52; $P=0.31$ ), Farias et al. [8] (RR 1.17, 95\% CI 0.85-1.61; $P=0.33$ ), Gianatti et al. [9] (RR 1.18, 95\% CI 0.90-1.55; 
Table 2 General features of the studies considered

\begin{tabular}{|c|c|c|c|c|c|}
\hline Study & Type of study & $\begin{array}{l}\text { Patient } \\
\text { enrollment } \\
\text { period } \\
\text { (years) }\end{array}$ & $\begin{array}{l}\text { No. of } \\
\text { patients } \\
\text { with low } \\
\text { TT }(n)\end{array}$ & $\begin{array}{l}\text { No. of } \\
\text { patients with } \\
\text { normal/high } \\
\text { TT }(n)\end{array}$ & $\begin{array}{l}\text { Low and normal/high } \\
\text { TT ranges }\end{array}$ \\
\hline Cheung et al. (2016) [7] & Observational & $2008-2011$ & 152 & 1087 & $<9$ and $\geq 9 \mathrm{nmol} / \mathrm{L}$ \\
\hline Farias et al. (2014) [8] & Observational & 2010-2012 & 35 & 78 & $\begin{array}{l}<12.1 \\
\quad \text { and } \geq 12.1 \mathrm{nmol} / \mathrm{L}\end{array}$ \\
\hline Gianatti et al. (2016) [9] & $\mathrm{RCT}$ & $2009-2013$ & 43 & 43 & Exogenous \\
\hline Hackett et al. (2016) [10] & RCT & 2007-2009 & 362 & 320 & $\leq 12$ and $>12 \mathrm{nmol} / \mathrm{L}$ \\
\hline Liu et al. (2013) [11] & Observational & 2008 & 249 & 517 & $<300$ and $\geq 300 \mathrm{ng} / \mathrm{dL}$ \\
\hline $\begin{array}{l}\text { Muraleedharan et al. (2013) } \\
\text { [12] }\end{array}$ & Observational & $2002-2005$ & 238 & 343 & $\leq 10.4$ and $>10.4 \mathrm{nmol} / \mathrm{L}$ \\
\hline
\end{tabular}

$T T$ testosterone, $R C T$ randomized controlled trial

Table 3 Baseline characteristics of the patients in each study

\begin{tabular}{|c|c|c|c|c|c|c|}
\hline Study & $\begin{array}{l}\text { Age } \\
\text { (years) } \\
\text { LT/NT }\end{array}$ & $\begin{array}{l}\text { Disease duration } \\
\text { (years) } \\
\text { LT/NT }\end{array}$ & $\begin{array}{l}\text { HBA1c } \\
(\%) \\
\text { LT/NT }\end{array}$ & $\begin{array}{l}\text { LDL }^{a} \\
\text { LT/ } \\
\text { NT }\end{array}$ & $\begin{array}{l}\mathbf{T C}^{\mathbf{b}} \\
\mathrm{LT} / \mathrm{NT}\end{array}$ & Testosterone level \\
\hline Cheung et al. (2016) [7] & $60.4 / 58.4$ & $10.0 / 10.0$ & $7.90 / 7.70$ & $\begin{array}{l}2.43 / \\
2.60\end{array}$ & $\begin{array}{r}4.48 / \\
4.55\end{array}$ & $<9 \mathrm{vs} \geq 9 \mathrm{nmol} / \mathrm{L}$ \\
\hline Farias et al. (2014) [8] & $59.0 / 58.0$ & $7.90 / 6.00$ & $7.05 / 6.90$ & $\begin{array}{r}127 / \\
118\end{array}$ & - & $\begin{array}{l}<12.1 \\
\quad \text { vs } \geq 12.1 \mathrm{nmol} / \mathrm{L}\end{array}$ \\
\hline Gianatti et al. (2016) [9] & $62.0 / 62.0$ & $7.00 / 9.00$ & $6.80 / 7.10$ & $\begin{array}{l}2.30 / \\
2.20\end{array}$ & $\begin{array}{r}4.20 / \\
4.50\end{array}$ & 10.6 vs $11.0 \mathrm{nmol} / \mathrm{L}$ \\
\hline Hackett et al. (2016) [10] & $65.5 / 64.2$ & - & $7.50 / 7.30$ & - & $\begin{array}{l}4.10 / \\
4.10\end{array}$ & $\begin{array}{l}\leq 12.0 \\
\quad \text { vs }>12.0 \mathrm{nmol} / \mathrm{L}\end{array}$ \\
\hline Liu et al. (2013) [11] & $65.6 / 60.5$ & $10.50 / 10.30$ & $7.40 / 7.30$ & $\begin{array}{r}86.7 / \\
92.3\end{array}$ & $\begin{array}{l}154 / \\
160.1\end{array}$ & 240 vs $420 \mathrm{ng} / \mathrm{dL}$ \\
\hline $\begin{array}{l}\text { Muraleedharan et al. (2013) } \\
\text { [12] }\end{array}$ & $60.3 / 58.9$ & - & $7.50 / 7.20$ & - & - & 7.5 vs $15.7 \mathrm{nmol} / \mathrm{L}$ \\
\hline
\end{tabular}

$L T$ low testosterone, $N T$ normal testosterone, $L D L$ low-density lipoprotein, $T C$ total cholesterol, $v s$ versus

a Reported in $\mathrm{mmol}$ or $\mathrm{mg} / \mathrm{dL}$

$P=0.23)$, Hackett et al. [10] (RR 1.31, 95\% CI 0.97-1.78; $P=0.08)$, and Muraleedharan et al. [12] (RR 1.30, 95\% CI 0.88-1.93; $P=0.19)$.
However, when the study by Liu et al. [11] was excluded, T2DM patients with a low testosterone level were found to be at a significantly 


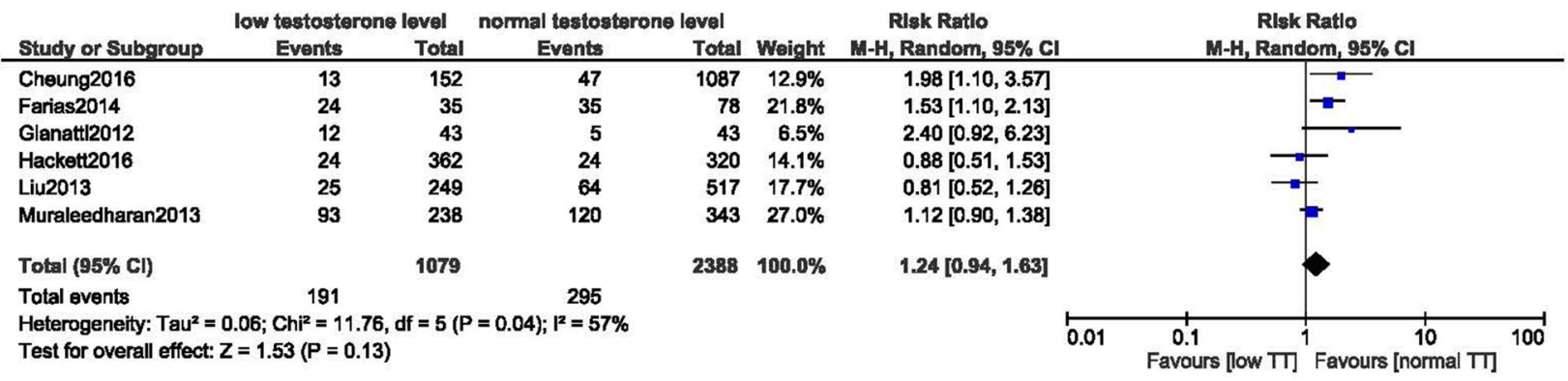

Fig. 2 Association of a low testosterone level with cardiovascular risk (using the random effects model)

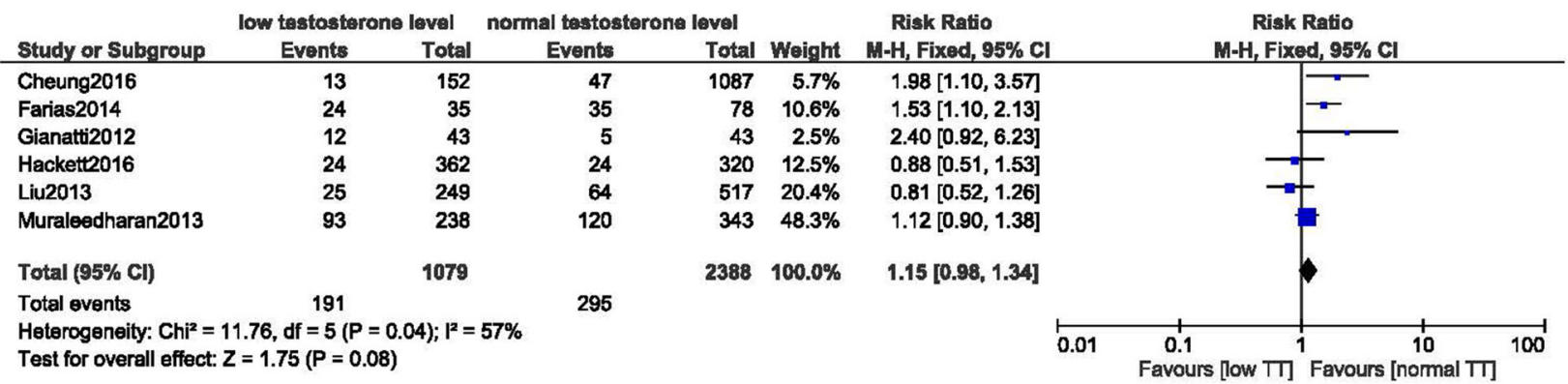

Fig. 3 Association of a low testosterone level with cardiovascular risk (using the fixed effects model)

higher risk of cardiovascular disease than those with a normal testosterone level (RR 1.35, 95\% CI 1.02-1.78; $P=0.04$ ).

\section{DISCUSSION}

Through this analysis, we aimed to show whether a decreased testosterone level was associated with a higher risk of $\mathrm{CAD} /$ cardiovascular disease in male patients with T2DM. Our results suggested that such a link was present, although, due to a lack of statistical significance, there was not enough evidence to prove this link.

Testosterone, which is derived from cholesterol, is the male sex hormone [13]. In the body, most testosterone is bound to protein (about $98 \%$ ), while some is present as free molecules (about 2\%). The free testosterone is readily available in the blood and is responsible for several major important functions in the male body. It is primarily synthesized in Leydig cells in the testes of the male sex organ [14]. In men, testosterone is responsible for secondary sexual features, it increases libido (sex drive), and it improves erectile function. It is also important for maintaining healthy vascular function throughout the body [15] and has other important functions which will not be discussed here [16]. A few studies have even shown testosterone to be modestly cardioprotective; possible mechanisms for this cardioprotective action have been proposed [17] and are listed in Table 4.

In brief, a high testosterone concentration may have anti-arrhythmic properties [17]. Testosterone might also decrease the QTc interval length, thus exerting a beneficial cardiovascular effect. This hormone may also reduce the size of an infarction in the cardiac muscle, further showing that it is cardioprotective. Studies have also shown that testosterone causes blood vessel vasodilation, which again has a positive effect on the cardiovascular system. Further, testosterone has been found to prevent plaque formation, thus protecting from atherosclerosis [17].

The association of a low testosterone level with CAD/cardiovascular disease is still controversial [4]. However, in support of the results of 


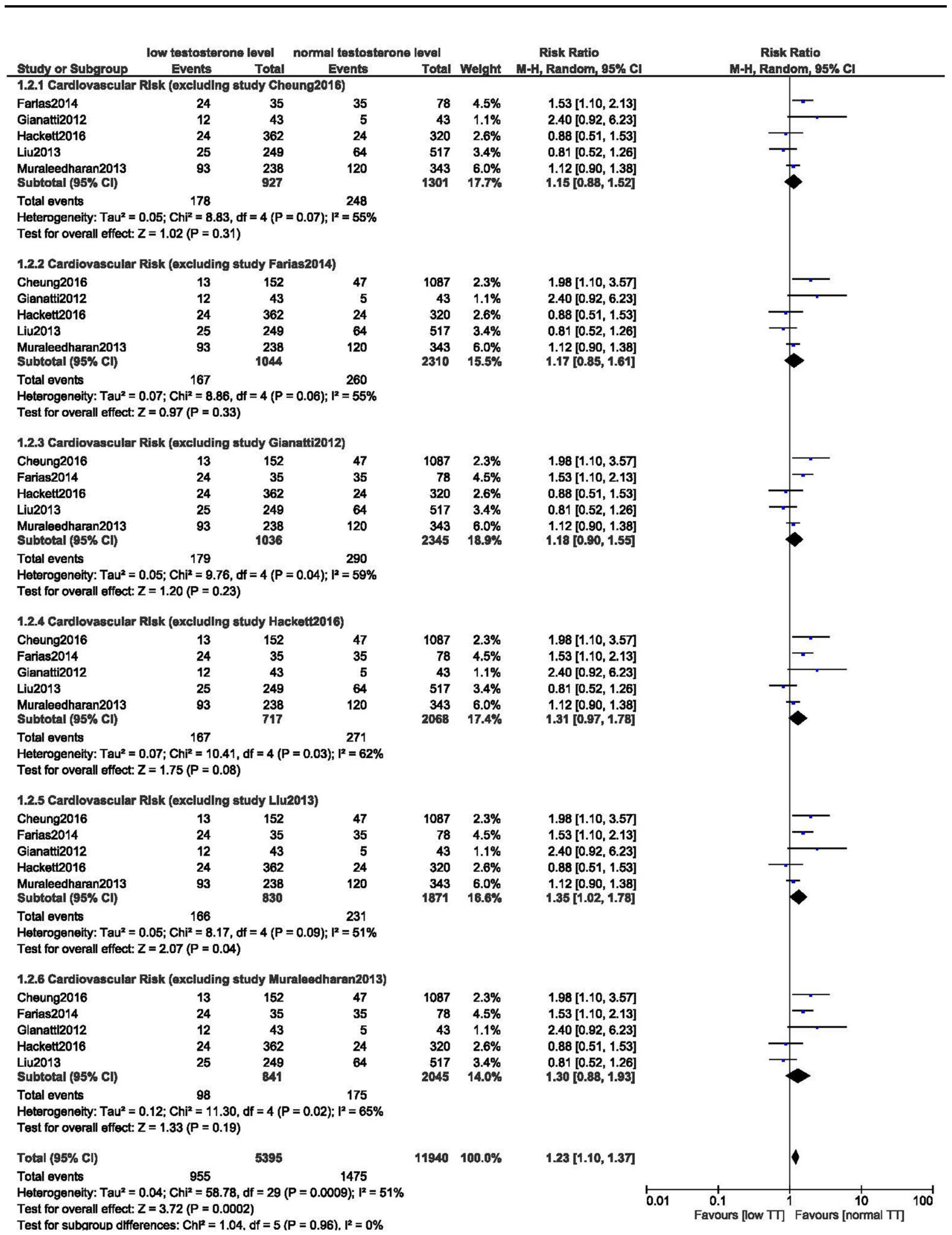

Fig. 4 Results of a sensitivity analysis performed using the exclusion method 
Table 4 Main mechanisms that link testosterone level to the risk of coronary artery disease

Testosterone..

1. Acts as an anti-arrhythmic agent, so it is cardioprotective

2. Reduces the size of a MI, so it is cardioprotective

3. Causes vasodilation of coronary vessels, so it is cardioprotective

4. May decrease QTc interval in the electrocardiogram

5. Prevents plaque formation, thus protecting from atherosclerosis

6. Reduces visceral fat accumulation and improves fasting glucose levels

7. May, according to some controversial reports, lead to blood vessel constriction at high doses, and may also increase inflammation, which could aggravate MI

$C A D$ coronary artery disease, $M I$ myocardial infarction

the present analysis, a Japanese study showed a direct link between testosterone deficiency and cardiovascular events [18]. The authors concluded that a low testosterone level was associated with cardiovascular events in middle-aged Japanese men, independent of coronary risk factors and endothelial function. In addition, a 13-year follow-up of former multiple risk factor intervention trial participants showed that a decreased endogenous testosterone level in men was associated with potentially unwanted changes in triglyceride level (increased) and high density lipoprotein (decreased), which could contribute to cardiovascular disease $[19,20]$.

Furthermore, Donner et al. found that a testosterone deficiency in diabetic patients was related to cardiovascular risk or outcomes [21]. However, their study was limited to animal models in which cardiovascular structure and function as well as myocardial tolerance were investigated. Daka et al. also showed that a low testosterone level predicted acute myocardial infarction in Swedish male patients with T2DM [22].

On the other hand, Hernández-Mijares et al. did not find any association between low testosterone and the risk of silent myocardial infarction or peripheral artery disease, even though their study showed that a low level of testosterone in diabetic male patients was associated with a high body mass index, a high waist circumference, neuropathy, and other unwanted conditions [23]. Nevertheless, a letter of correspondence to Hernández-Mijares et al. revealed that the use of oral hypoglycemic agents and other confounding factors may have contributed to the fact that no association was observed between cardiovascular risk and a low testosterone level in his patients with T2DM [24].

It should also not be ignored that clinical research has shown that testosterone interacts with thrombophilia-hypofibrinolysis, leading to thrombosis. So, decreasing the testosterone level would prevent testosterone-associated thrombosis, thus lowering the incidence of cardiovascular disease. Further, it is known that platelet aggregation and stimulation of the coagulation pathway play important roles in thrombus formation, and in vitro studies in animal models have shown that reducing testosterone decreases platelet aggregation and thromboxane A2 receptor density, thereby reducing the incidence of cardiovascular disease [25]. Even when given at a physiological dosage, testosterone was shown to increase platelet aggregation [26]. Apart from platelet aggregation, testosterone also promotes coagulation by affecting coagulation factors that are implicated in the fibrinolytic pathway, resulting in an increased level of plasminogen activator inhibitor-1 and thus a higher risk of cardiovascular manifestations due to reduced fibrinolysis [27]. 
Oral hypoglycemic agents as well as statins have been found to affect the testosterone level in male patients with T2DM. While metformin is believed to reduce the total testosterone level in male patients with T2DM [28], glimepiride might, in contrast, help to recover the decreased testosterone level [29], whereas the involvement of statins in reducing the testosterone level is still doubtful [30]. Some of the possible iatrogenic causes of testosterone modulation in patients with diabetes mellitus are given in Table 5.

A decreased testosterone level has also been shown to increase vascular disease risk in men with hypogonadotropic hypogonadism by indirectly increasing triglyceride levels and lowdensity lipoprotein levels and decreasing highdensity lipoproteins in the blood, which may ultimately contribute to the development of coronary artery disease [31]. In men who are on antiandrogen therapy (for example patients with prostate cancer), a decreased testosterone level may indirectly contribute to cardiovascular diseases, as previously mentioned [32]. In patients with diabetes mellitus, other factors involving different mechanisms could further raise low-density lipoprotein levels and promote platelet hyperactivity, contributing to cardiovascular diseases [33].

Nevertheless, cardiovascular disease is one of the main complications that arise in patients with diabetes mellitus. Thus, we believe that the time has come to review the relationship between testosterone level and cardioembolism,

Table 5 Some of the possible iatrogenic causes of testosterone modulation in patients with diabetes mellitus

\begin{tabular}{ll}
\hline $\begin{array}{l}\text { Medications used in } \\
\text { patients with diabetes } \\
\text { mellitus }\end{array}$ & $\begin{array}{l}\text { Effect of the medications } \\
\text { on the testosterone level }\end{array}$ \\
\hline Biguanides & Reduce it \\
Sulfonylurea & Stabilizes it at normal level \\
Alpha-glucosidase inhibitors & $\begin{array}{l}\text { Reduce it } \\
\text { Thiazolidinediones }\end{array}$ \\
Insulin & Reduce it \\
\hline
\end{tabular}

given that the testosterone level decreases with age and the use of testosterone ointment by the elderly is rising due to an increased rate of erectile dysfunction.

\section{Novelty}

This study is new because it is the first metaanalysis to show that a low level of testosterone is a risk factor for CAD/cardiovascular disease in patients with T2DM. The results of this study may inspire other scientists to investigate this matter further, given that this is potentially an important finding that could be utilized in clinical medicine. Finally, since it is a new idea in the field of cardiovascular diabetology, this analysis is a novelty in itself.

\section{Limitations}

The limited sample size of the population analyzed may have influenced the results. In addition, one of the studies considered in this metaanalysis also involved patients who were being treated with testosterone; however, because that study satisfied the inclusion and exclusion criteria, it was included in the analysis. Moreover, a moderate level of heterogeneity was observed during the subgroup analysis. This may have been due to the inclusion of observational data and other heterogeneous reported data. Also, the range of testosterone levels varied depending on the study, which could be another major limitation of this analysis. In addition, the analysis only focused on a particular subgroup of patients with T2DM who did not represent the general population of patients. Another limitation is the fact that old age is associated with a decreased level of testosterone; this would have acted as a confounding factor, possibly affecting the results.

\section{CONCLUSION}

A previously or currently decreased testosterone level did not show a statistically significant association with a higher risk of CAD/cardiovascular disease in male patients with T2DM, 
although the difference in risk between the T2DM patients with low and normal testosterone levels was observed to approach statistical significance. The limited number of patients analyzed was not sufficient to prove this association, thus warranting further investigations.

\section{ACKNOWLEDGEMENTS}

Funding. The research for this study was supported by grants from the National Natural Science Foundation of China (no. 81560046), the Guangxi Natural Science Foundation (no. 2016GXNSFAA380002), the Scientific Project of Guangxi Higher Education (no. KY2015ZD028), the Science Research and Technology Development Project of Qingxiu District of Nanning (no. 2016058), and the Lisheng Health Foundation pilotage fund of Peking (no. LHJJ20158126). No funding was received for the article processing charges.

Authorship. Feng Huang was responsible for the conception and design of this meta-analysis, the acquisition of data, and the analysis and interpretation of the data, as well as for drafting the initial manuscript and revising it critically for important intellectual content. Feng Huang wrote this manuscript. All of the named authors meet the International Committee of Medical Journal Editors (ICMJE) criteria for authorship for this article, take responsibility for the integrity of the work as a whole, and have given their approval for this version to be published.

\section{Disclosures. Feng Huang has nothing to declare.}

Compliance with Ethical Guidelines. This meta-analysis is based on previously conducted studies and does not contain any studies with human participants or animals performed by any of the authors.

Data Availability. All data generated or analyzed during this study are included in this published article.
Open Access. This article is distributed under the terms of the Creative Commons Attribution-NonCommercial 4.0 International License (http://creativecommons.org/licenses/ by-nc/4.0/), which permits any noncommercial use, distribution, and reproduction in any medium, provided you give appropriate credit to the original author(s) and the source, provide a link to the Creative Commons license, and indicate if changes were made.

\section{REFERENCES}

1. Tan KH, Barr ELM, Koshkina V, Ma S, Kowlessur S, Magliano DJ, Söderberg S, Chia KS, Zimmet P, Lim WY. Diabetes mellitus prevalence is increasing in South Asians but is stable in Chinese living in Singapore and Mauritius. J Diabetes. 2017;9(9):855-64.

2. Islam GM. The risk of developing cardiovascular disease in Bangladesh: does diabetes mellitus matter? Which socioeconomic status does it impact? A cross sectional study. J Am Soc Hypertens. 2017;11(1):45-53.e1.

3. Tambo A, Roshan MH, Pace NP. Testosterone and cardiovascular disease. Open Cardiovasc Med J. 2016;15(10):1-10.

4. Corona G, Mannucci E, Forti G, Maggi M. Hypogonadism, ED, metabolic syndrome and obesity: a pathological link supporting cardiovascular diseases. Int J Androl. 2009;32(6):587-98.

5. Liberati A, Altman DG, Tetzlaff J, et al. The PRISMA statement for reporting systematic reviews and meta-analyses of studies that evaluate health care interventions: explanation and elaboration. BMJ. 2009;339:b2700.

6. Higgins JPT, Thompson SG, Deeks JJ, Altman DG. Measuring inconsistency in meta-analyses. BMJ. 2003;327(7414):557-60.

7. Cheung KK, Lau ES, et al. Low testosterone and clinical outcomes in Chinese men with type 2 diabetes mellitus-Hong Kong Diabetes Registry. Diabetes Res Clin Pract. 2017;123:97-105. http://dx. doi.org/10.1016/j.diabres.2016.11.012.

8. Farias JM, Tinetti M, Khoury M, Umpierrez GE. Low testosterone concentration and atherosclerotic disease markers in male patients with type 2 diabetes. J Clin Endocrinol Metab. 2014;99(12):4698-703. 
9. Gianatti EJ, Hoermann R, Lam Q, Dupuis P, Zajac JD, Grossmann M. Effect of testosterone treatment on cardiac biomarkers in a randomized controlled trial of men with type 2 diabetes. Clin Endocrinol (Oxf). 2016;84(1):55-62.

10. Hackett G, Heald AH, Sinclair A, Jones PW, Strange RC, Ramachandran S. Serum testosterone, testosterone replacement therapy and all-cause mortality in men with type 2 diabetes: retrospective consideration of the impact of PDE5 inhibitors and statins. Int J Clin Pract. 2016;70(3):244-53.

11. Liu RT, Chung MS, Wang PW, Chen CD, Lee JJ, Lee WC, Chancellor MB, Yang KD, Chuang YC. The prevalence and predictors of androgen deficiency in Taiwanese men with type 2 diabetes. Urology. 2013;82(1):124-9.

12. Muraleedharan V, Marsh H, Kapoor D, Channer KS, Jones TH. Testosterone deficiency is associated with increased risk of mortality and testosterone replacement improves survival in men with type 2 diabetes. Eur J Endocrinol. 2013;169(6):725-33.

13. Hou JW, Collins DC, Schleicher RL. Sources of cholesterol for testosterone biosynthesis in murine Leydig cells. Endocrinology. 1990;127(5):2047-55.

14. Zouboulis CC, Degitz K. Androgen action on human skin-from basic research to clinical significance. Exp Dermatol. 2004;13(Suppl 4):5-10.

15. Oskui PM, French WJ, Herring MJ, Mayeda GS, Burstein S, Kloner RA. Testosterone and the cardiovascular system: a comprehensive review of the clinical literature. J Am Heart Assoc. 2013;2(6):e000272.

16. Ammar EM, Said SA, Hassan MS. Enhanced vasoconstriction and reduced vasorelaxation induced by testosterone and nandrolone in hypercholesterolemic rabbits. Pharmacol Res. 2004;50(3):253-9.

17. Herring MJ, Oskui PM, Hale SL, Kloner RA. Testosterone and the cardiovascular system: a comprehensive review of the basic science literature. J Am Heart Assoc. 2013;2(4):e000271.

18. Akishita M, Hashimoto $M$, Ohike $Y$, Ogawa S, Iijima $\mathrm{K}$, Eto M, Ouchi Y. Low testosterone level as a predictor of cardiovascular events in Japanese men with coronary risk factors. Atherosclerosis. 2010;210(1):232-6.

19. Zmuda JM, Cauley JA, Kriska A, Glynn NW, Gutai JP, Kuller LH. Longitudinal relation between endogenous testosterone and cardiovascular disease risk factors in middle-aged men. A 13-year followup of former Multiple Risk Factor Intervention Trial participants. Am J Epidemiol. 1997;146(8):609-17.
20. Lim TS, Yun JS, Cha SA, Song KH, Yoo KD, Ahn YB, Park YM, Ko SH. Elevated lipoprotein(a) levels predict cardiovascular disease in type 2 diabetes mellitus: a 10-year prospective cohort study. Korean J Intern Med. 2016;31(6):1110-9.

21. Donner DG, Elliott GE, Beck BR, Bulmer AC, Du Toit EF. Impact of diet-induced obesity and testosterone deficiency on the cardiovascular system: a novel rodent model representative of males with testosterone-deficient metabolic syndrome (TDMetS). PLoS One. 2015;10(9):e0138019.

22. Daka B, Langer RD, Larsson CA, Rosén T, Jansson $\mathrm{PA}$, Råstam L, Lindblad U. Low concentrations of serum testosterone predict acute myocardial infarction in men with type 2 diabetes mellitus. BMC Endocr Disord. 2015;25(15):35.

23. Hernández-Mijares A, García-Malpartida K, SoláIzquierdo E, Bañuls C, Rocha M, Gómez-Martínez MJ, Mármol R, Víctor VM. Testosterone levels in males with type 2 diabetes and their relationship with cardiovascular risk factors and cardiovascular disease. J Sex Med. 2010;7(5):1954-64.

24. Li H, Kong XB, Zhang HL, Wu J. Testosterone levels in males with type 2 diabetes and their relationship with cardiovascular risk factors and cardiovascular diseases. J Sex Med. 2011;8(4):1260.

25. Matsuda K, Ruff A, Morinelli TA, Mathur RS, Halushka PV. Testosterone increases thromboxane A2 receptor density and responsiveness in rat aortas and platelets. Am J Physiol. 1994;267(3 Pt 2):H887-93.

26. Ajayi AA, Mathur R, Halushka PV. Testosterone increases human platelet thromboxane $\mathrm{A} 2$ receptor density and aggregation responses. Circulation. 1995;91(11):2742-7.

27. Phillips GB, Pinkernell BH, Jing TY. The association of hypotestosteronemia with coronary artery disease in men. Arterioscler Thromb. 1994;14(5):701-6.

28. Ozata M, Oktenli C, Bingol N, Ozdemir IC. The effects of metformin and diet on plasma testosterone and leptin levels in obese men. Obes Res. 2001;9(11):662-7.

29. Wong Long, Chen Hong-Mei, Lai Shui-Qing, Yang Hua-Zhang, Kuang Jian, Pei Jian-Hao. Effects of sulfonylurea as initial treatment on testosterone of middle-aged men with type 2 diabetes: a 16-week, pilot study. J Diabetes Investig. 2015;6(4):454-9.

30. Sniderman AD, Thanassoulis G. Do statins lower testosterone and does it matter? BMC Med. 2013;28(11):58. 
31. Traish AM, Haider A, Doros G, Saad F. Long-term testosterone therapy in hypogonadal men ameliorates elements of the metabolic syndrome: an observational, long-term registry study. Int J Clin Pract. 2014;68(3):314-29.

32. Bhatia N, Santos M, Jones LW, Beckman JA, Penson DF, Morgans AK, Moslehi J. Cardiovascular effects of androgen deprivation therapy for the treatment of prostate cancer: ABCDE steps to reduce cardiovascular disease in patients with prostate cancer. Circulation. 2016;133(5):537-41.

33. Nadal JF, Gutiérrez PC. Type 2 diabetes mellitus and cardiovascular risk factors: is comprehensive treatment required? Med Clin (Barc). 2013;141(Suppl 2):7-13. 